\title{
Risk-based assessment of arsenic-affected aquacultural water in blackfoot disease hyperendemic areas
}

\author{
Cheng-Shin Jang · Kao-Hung Lin · Chen-Wuing Liu • \\ Ming-Chao Lin
}

Published online: 31 May 2008

(C) Springer-Verlag 2008

\begin{abstract}
This work explored a risk-based arsenic (As) regulation in farmed pond water by ingesting tilapia (Oreochromis mossambicus) in blackfoot disease hyperendemic areas and discussed a rational As regulation in pond water. Monte Carlo analysis was used to propagate the parameter uncertainty and to assess probabilistically regulation risks. A dynamic scheme of groundwater management was proposed that curves of utilization ratios against As concentrations in groundwater were established based on the risk-based regulation. The 5th to 95th percentiles of risks range from $3.5 \times 10^{-7}$ to $6.0 \times 10^{-5}$ via ingesting the farmed tilapia under the current As regulation in farmed pond water in Taiwan, $50 \mu \mathrm{g} / \mathrm{L}$. To compare to inorganic As regulation in drinking water, the current As regulation in farmed pond water does not pose a great threat to human health, but it is unsafe. Therefore, this study suggests that the regulation of As in farmed pond water is revised to be $25 \mu \mathrm{g} / \mathrm{L}$.
\end{abstract}

C.-S. Jang

Department of Leisure and Recreation Management,

Kainan University, Luzhu, Taoyuan 33857, Taiwan, ROC

K.-H. Lin

Sustainable Environment Research Center,

National Cheng Kung University, Tainan 701, Taiwan, ROC

C.-W. Liu $(\bowtie)$

Department of Bioenvironmental Systems Engineering, National Taiwan University, Taipei 106, Taiwan, ROC

e-mail: lcw@gwater.agec.ntu.edu.tw

M.-C. Lin

General Education Center, Graduate Institute of Environmental Management, Nanhua University, Dalin, Chia-Yi 62248,

Taiwan, ROC
Keywords Groundwater - Risk-based management . Aquacultural water $\cdot$ Uncertainty

\section{Introduction}

Arsenic (As) has been well documented to be a major risk factor for blackfoot disease (BFD) (Chen et al. 1994). Blackfoot disease was once epidemic on the southwestern coast of Taiwan (Tseng 1977). The residents used artesian well water with a high As content for over 50 years. Largescale investigations on the association between As complexes in well water and age-adjusted mortality from several diseases (Lai et al. 1994; Chen et al. 1995) and cancers (Wu et al. 1989; Chen and Wang 1990) yield mutually supporting findings. Most patients are concentrated in few townships which are named as BFD hyperendemic areas.

Arsenic concentrations are abnormally high in BFD hyperendemic areas. Tseng (1977) reported that As concentrations in groundwater were $10-1,840 \mu \mathrm{g} / \mathrm{L}$ in these areas and most of them ranged from 400 to $600 \mu \mathrm{g} / \mathrm{L}$. A survey of domestic drinking-water wells in the BFD hyperendemic area also indicated that As contents ranged from $<10$ to $2,930 \mu \mathrm{g} / \mathrm{L}$ (ITRI 1993). Jang et al. (2006) used As concentrations of $<10$ to $1,470 \mu \mathrm{g} / \mathrm{L}$ in groundwater around BFD hyperendemic areas to analyze spatially potential carcinogenic risks associated with ingesting As in aquacultural tilapia. Groundwater is used abundantly for several utilities and is an alternative to surface water in coastal regions of southwestern Taiwan, where surface water resources are severely deficient. Nowadays, most inhabitants in these regions do not drink well water directly since many epidemiological evidences prove that the As exposure is strongly related to the incidence of diseases and cancers. However, very large quantities of groundwater are 
used to farm fish and shellfish. Tilapia (Oreochromis mossambicus) is one of the most favored edible fish in Taiwan and is mainly cultured in BFD hyperendemic areas. Arsenic in groundwater indirectly enters the food-chain via various paths and bio-accumulates in humans. Han et al. (1998) found total As concentrations of 0.13-1.45 $\mu \mathrm{g} / \mathrm{g}$ dry wt bio-accumulated in tilapia in the BFD hyperendemic areas of Taiwan. Liao and Ling (2003) reported total As concentrations of $26.3 \pm 16$ to $251.7 \pm 12.2 \mu \mathrm{g} / \mathrm{L}$ in pond water and $0.94 \pm 0.3$ to $15.1 \pm 8.2 \mu \mathrm{g} / \mathrm{g}$ dry wt in farmed tilapia in these regions.

The occurrence of As in drinking water and food is an issue of considerable public health interest (Yu et al. 2007). Risk assessment is a frequently employed method which discusses potential threats to human health through an exposure-bioaccumulation-ingestion pathway of toxic substances in aquatic organisms (Pohl et al. 2003; Hung et al. 2004). Several researches evaluated by the risk assessment approach revealed that the great amount of ingesting tilapia farmed in the BFD hyperendemic area posed a menace to human health (Han et al. 1998; Liao and Ling 2003; Liu et al. 2005; Ling et al. 2005; Jang et al. 2006). Additionally, a regulatory standard of As in farmed pond water is $50 \mu \mathrm{g} / \mathrm{L}$ in Taiwan (Taiwan EPA 1998). Arsenic concentrations in many ponds far exceed the standard (Liao and Ling 2003). Moreover, the Taiwanese regulatory standard of As in farmed pond water is lack of scientific evidences to demonstrate that it is no adverse health effects. Recently, many researches focused on discussing a risk-based regulation of As in soil and drinking water (Zakharova et al. 2002; Yu et al. 2003; Benner 2004; Cao et al. 2008), but paid little attention to examining a risk-based regulation of As in farmed fish ponds.

Many Taiwanese rather care about the information of public health issues and risks on fish consumption. The risks are frequently determined according to experimental data and modelling assumptions. However, only a small proportion of in-situ data can be analyzed in a survey owing to time and cost constraints. Risk predictions made with sparse measurement data are typically subject to considerable uncertainty (Yu et al. 2007). Moreover, overestimated risks lead to social panic and fisher's economic losses. Accordingly, probabilistic risk assessment can avoid making an assertive conclusion of public health issues (Kentel and Aral 2005). Both average and extreme levels of risks are considered in probabilistic risk assessment, which provides a sound framework to explore risk information on human health (US EPA 2006).

The objective of this work was to evaluate a risk-based regulation of As in farmed pond water via As bioaccumulation of tilapia (Oreochromis mossambicus) in BFD hyperendemic areas. First, Monte Carlo analysis (MCA) was used to propagate the uncertainty of parameters. A series of joint distributions of parameters were obtained in processes of probabilistic risk assessment. Then, according to our bioaccumulation data of tilapia, this work compared inorganic As contents in farmed tilapia with those in drinking water under conditions of current As regulations of pond water and drinking water. A novel As regulation standard in pond water was established based on the bioaccumulation relationship of inorganic As contents between tilapia and drinking water. Moreover, a scheme of risk management involving groundwater use was suggested based on the riskbased regulation of As in farmed fish ponds. The analyzed results can facilitate administrators to make robust policies associated with aquacultural safety and sound groundwater management in the BFD hyperendemic areas.

\section{Materials and methods}

\subsection{Study area}

Blackfoot disease primarily occurs in the Yichu, Hsuehchia, Putai and Peimen townships, located in the coastal region of Chianan plain (Fig. 1). In the regions, aquaculture is the primary source of revenue for the inhabitants. A large amount of As-contaminated groundwater has been extracted from aquifers to supply fishponds.

Changes in sea level significantly influence the composition and structure of the geological environment in the shallow sedimentary basin of southwestern Taiwan (Liu et al. 2006). The sedimentary basin is formed by the alternating invasion and retreat of sea-water with mixing formations of marine and non-marine sequences. The hydrogeological analysis demonstrates that the area is formed in the late Quaternary age (Taiwan Sugar Company 2002). The non-marine sequences with high permeability can be considered to be aquifers. The marine sequences with fine sediments can be regarded as aquitards in which a

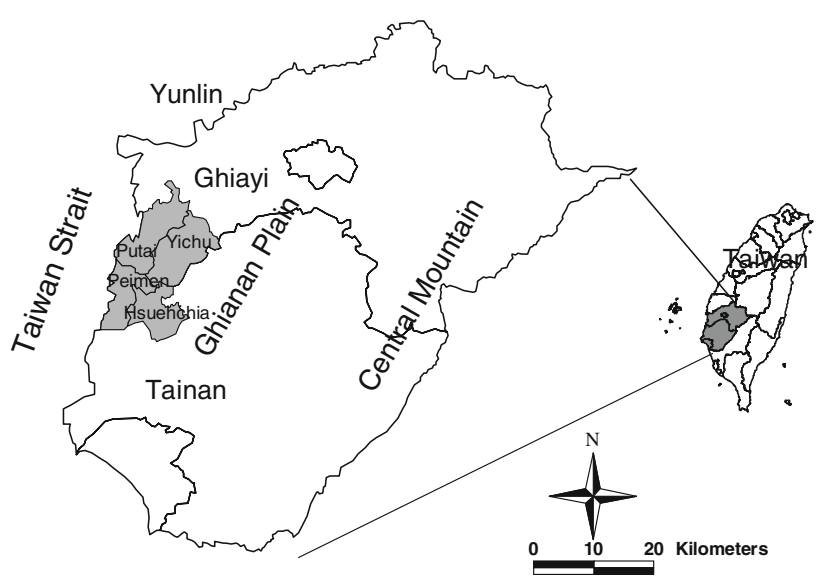

Fig. 1 BFD hyperendemic areas (gray color) in southwestern Taiwan 
relatively high As content is accumulated and deposited (Liu et al. 2006). Many small and discontinuous aquitards present in the formation of the Chianan plain, resulting in high As concentrations in groundwater.

\subsection{Arsenic bioaccumulation in tilapia}

Arsenic contents in fish are a result of bioaccumulation in fishpond environments which is named as bio-concentration (McGeer et al. 2003). The As concentration in tilapia is expressed as follows:

$C_{\text {tilapia }}=B C F \times C_{\text {pond }}$

where $C_{\text {tilapia }}$ is the As content $(\mu \mathrm{g} / \mathrm{kg}$ dry wt) in the edible portion of tilapia and $C_{p o n d}$ is the As concentration $(\mu \mathrm{g} / \mathrm{L})$ in pond water. The $B C F$ is the bio-concentration factor. Figure 2a shows data of $B C F$ in the BFD hyperendemic areas and Table 1 provides the statistics and distribution of $B C F$. The detailed experimental processes, chemical assay, recovery rates and data on tilapia were introduced in our previous researches, Huang et al. (2003) and Lin (2004).

\subsection{Risk assessment of human health via ingesting tilapia}

Generally, inorganic As species, arsenite(III) and arsenate $(\mathrm{V})$, are more toxic than organic As species, arsenobetaine, arsenocholine, MMA, DMA, arsenosugar, and arsenolipid (Mandal and Suzuki 2002; Oremland and Stotlz 2003). The organic As forms are considered practically as a lower toxicity or non-toxicity (Shiomi et al. 1996). Thus, the US EPA (1988) recommended that the uptake of inorganic As by various seafood species was used to determine potential risks to human health. The US EPA Region III Risk-Based Concentration Table supports a method for estimating the target cancer risk (TR) (US EPA 1988, 2001, 2006). The risk of carcinogenic effects of inorganic As is expressed as exceeding the probability of contracting the cancer over a lifetime of 70 years. A model for estimating the target cancer risks (lifetime cancer risks) via ingesting tilapia is (US EPA 2001),

$T R_{t}=\frac{E F r \times E D \text { tot } \times I R_{t} \times C_{i t} \times C P S o}{B W a \times A T c} \times 10^{-3}$

where $T R_{t}$ is the target cancer risk (the incremental individual lifetime cancer risk) via ingesting tilapia; $E F r$ is the exposure frequency (350 days/years); EDtot is the exposure duration (30 years); $I R_{t}$ is the ingestion rate in the edible portion of tilapia (g/day wet wt); $C_{i t}$ is the inorganic As concentration in the edible portion of tilapia $(\mu \mathrm{g} / \mathrm{g}$ wet $\mathrm{wt})$; CPSo is the oral carcinogenic potency slope [risk per $(\mathrm{mg} /$ $\mathrm{kg} /$ day $)]\left[1.5(\mathrm{mg} / \mathrm{kg} / \mathrm{day})^{-1}\right] ; B W a$ is the body weight of a Taiwanese adult $(\mathrm{kg})$, and $A T C$ is the averaging time for carcinogens (25,550 days).
Fig. 2 Observed distributions of tilapia experiment parameters in risk assessment
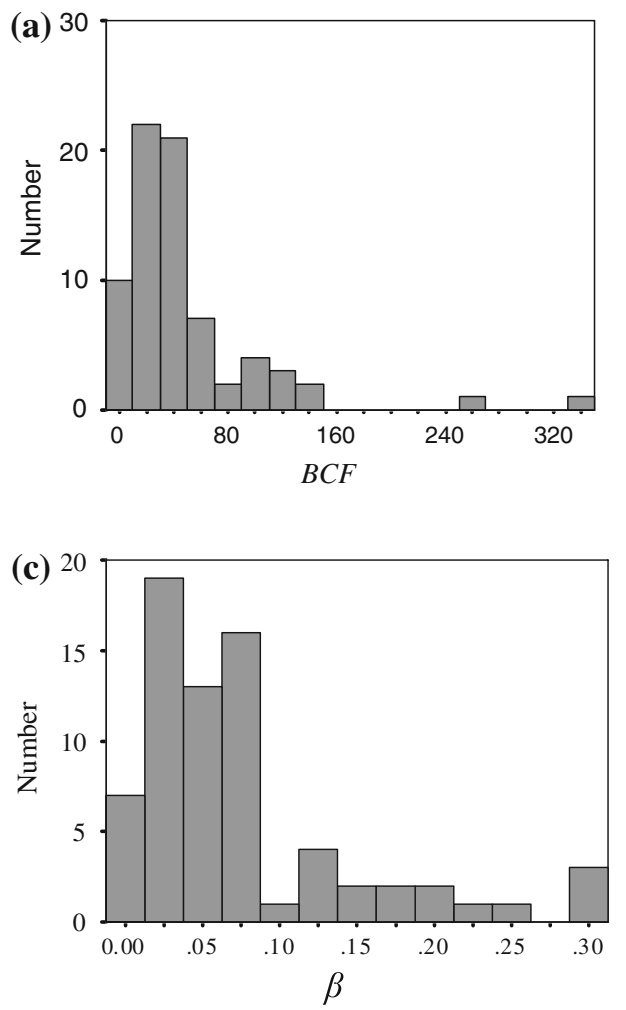
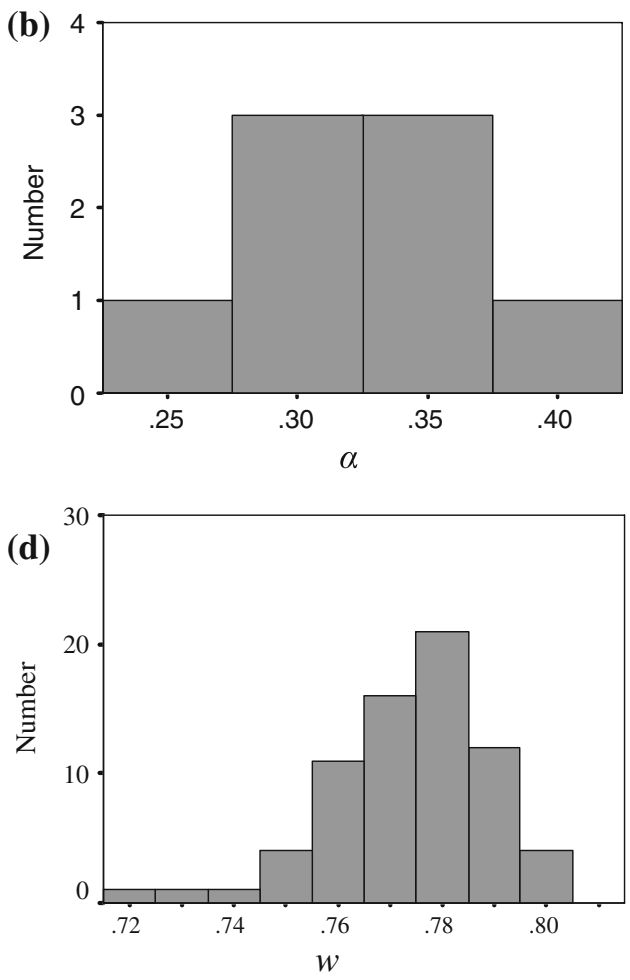
Table 1 Parameters and their distributions on risks of cancer

\begin{tabular}{llll}
\hline Parameters & Data number & Distributions & Data sources \\
\hline$B W a(\mathrm{~kg})$ & 2,422 males & $\mathrm{N}(60.9,9.9)^{\mathrm{a}}$ & Taiwan DOH (1997) \\
$\alpha$ & 2,435 females & $\mathrm{N}(0.32,0.046)$ & Lin (2004) \\
$\beta$ & 8 & $\mathrm{LN}(0.05,2.71)^{\mathrm{b}}$ & Huang et al. (2003) \\
$w$ & 68 & $\mathrm{~N}(0.773,0.016)$ & Huang et al. (2003) \\
$B C F$ & 68 & $\mathrm{LN}(29.1,3.07)$ & Huang et al. (2003) and Lin (2004) \\
$I R_{w t}(\mathrm{~g} /$ day wet wt) & 76 & $\mathrm{LN}(96.0,1.92)^{\mathrm{c}}$ & Liao and Ling (2003) \\
${ }^{\mathrm{a}} \mathrm{N}\left(\mu_{\mathrm{a}}, \sigma_{\mathrm{a}}\right)$ denotes a normal distribution with an arithmetic average of $\mu_{\mathrm{a}}$ and an arithmetic standard deviation of $\sigma_{\mathrm{a}}$ \\
${ }^{\mathrm{b}} \mathrm{LN}\left(\mu_{\mathrm{g}}, \sigma_{\mathrm{g}}\right)$ denotes a log-normal distribution with a geometric average of $\mu_{\mathrm{g}}$ and a geometric standard deviation of $\sigma_{\mathrm{g}}$ \\
${ }^{\mathrm{c}} \mathrm{Valid}$ range from 48 to $169 \mathrm{~g}$ /day wet wt
\end{tabular}

Equation (2) can be rewritten using the aforementioned parameters and the parameters of the experiment on tilapia (Jang et al. 2006).

$$
\begin{aligned}
T R_{t}= & \frac{I R_{t} \times C_{i t}}{B W a} \times 6.16 \times 10^{-4} \\
= & \frac{\left(I R_{w t} \times \alpha\right) \times\left[\left(\frac{C_{R P W}}{1000} \times B C F\right) \times \beta \times(1-w)\right]}{B W a} \\
& \times 6.16 \times 10^{-4}
\end{aligned}
$$

where $I R_{w t}$ is the ingestion rate of whole tilapia (g/day wet wt); $\alpha$ is the edible ratio of tilapia; $C_{R P W}$ is the regulation of As in farmed pond water $(\mu \mathrm{g} / \mathrm{L}) ; \beta$ is the ratio of inorganic As contents to total As contents in tilapia, and $w$ is the water content of tilapia. The term $(1-w)$ converts the dry wt As content to wet wt.

Jang et al. (2006) presented variations and distributions of these parameters used in Eq. (3). Figure 2 exhibited observed distributions of experiment parameters in tilapia and Table 1 listed statistical distributions of the parameters and sources of the data. The distributions of the parameters were identified using a Kolmogorov-Smirnov (K-S) test. An arithmetic average $B W a$ was $60.9 \mathrm{~kg}$ with an arithmetic standard deviation of $9.9 \mathrm{~kg}$ (Taiwan DOH 1997). According to experimental data reported in Huang et al. (2003) and Lin (2004), the arithmetic average $\alpha$ was 0.32 with the arithmetic standard deviation of 0.046 ; the geometric average $\beta$ was 0.05 with the geometric standard deviation of 2.71; and the arithmetic average $w$ was 0.773 with the arithmetic standard deviation of 0.016 . The geometric average $B C F$ was 29.1 with the geometric standard deviation of 3.07.

Since the occurrence of BFD is strongly related to a regional environment property, making a sound aquacultural policy involving no adverse health effects has to consider particularly exposed risks of residents living in the high hazard-prone region. Accordingly, as for the ingestion rate of tilapia, Liao and Ling (2003) reported a questionnaire survey result regarding tilapia consumption for 57 subsistence fishers in the BFD hyperendemic area. The ingestion rate of whole tilapia ranges from 48 to $169 \mathrm{~g} /$ day wet wt. This study compiled the data on the ingestion rates of whole tilapia which followed a log-normal distribution with a geometric mean of 96.0 g/day wet wt and a geometric standard deviation of $1.92 \mathrm{~g} /$ day wet wt [that is, LN(96.0, 1.92)].

Owing to sparse observed data in the tilapia experiment, robust data concerning the experimental parameters were generated using MCA based on their measured distributions and properly accounted for their uncertainty (Goovaerts et al. 2001; US EPA 2001; Kentel and Aral 2005). The @Risk (Version 4.5, Professional Edition, Palisade Crop., USA) software was used to analyze statistically the measured data and to carry out MCA.

\subsection{Mass balance of arsenic in ponds}

Water sources for aquacultural ponds are generally surface water and ground water adjacent to the ponds. The mass balance of As among groundwater, surface water and pond water is expressed as follows.

$$
\begin{aligned}
C_{\text {pond }} \times Q_{\text {pond }}= & C_{\text {groundwater }} \times Q_{\text {groundwater }}+C_{\text {surface }} \\
& \times Q_{\text {surface }}
\end{aligned}
$$

where $C_{\text {groundwater }}, C_{\text {pond }}$ and $C_{\text {surface }}$ are the As concentrations in groundwater, surface water and pond water, respectively, and $Q_{\text {groundwater }}, Q_{\text {surface }}$ and $Q_{\text {pond }}$ are the volumes of groundwater, surface water and pond water, respectively. The $Q_{\text {pond }}$ is the sum of $Q_{\text {groundwater }}$ and $Q_{\text {surface }}$. The term $Q_{\text {groundwater }} / Q_{\text {pond }}$ is defined as the dilution ratio $(D R)$ using surface water. The As concentrations in Eq. (4) was further rewritten as follows.

$C_{\text {pond }}=C_{\text {groundwater }} \times D R+C_{\text {surface }} \times(1-D R)$

Typically, arsenic of groundwater is the most primary As source in aquacultural ponds. The sources of surface water include river, sea and rainfall. According to survey 
data published by Taiwan EPA (http://wq.epa.gov.tw/wq/ Public2/ ImageBasin.asp), average As contents in rivers of the BFD hyperendemic regions and the coast range from 4.5 to $9.6 \mu \mathrm{g} / \mathrm{L}$ and from 0.8 to $2.0 \mu \mathrm{g} / \mathrm{L}$, respectively, during 2002-2006. The As concentration in rainfall can be considered to be nil. In the BFD hyperendemic regions, surface water has lower As concentrations than groundwater does.

\section{Results and discussion}

\subsection{Risks via ingesting tilapia farmed in pond water}

This work probabilistically considered five parameters $B C F, \beta, w, B W a$ and $I R_{w t}$-in risk assessment, except for $\alpha$ owing to sparse measured data. The five parameters followed either a normal distribution or a log-normal distribution, which was a two-parameter distribution. Before MCA implemented, an arithmetic average and an arithmetic standard deviation determine normal distributions, while a geometric average and a geometric standard deviation determine log-normal distributions. Additionally, this work used the arithmetic average of $\alpha, 0.32$, in the following analyzed processes.

To propagate their uncertainty, the five parameters in risk assessment were reproduced individually one thousand data using MCA based on their observed distributions. A series of joint distributions integrating the aforementioned parameters were carried out (Goovaerts et al. 2001; Jang et al. 2006). Figure 3 showed a detailed combining procedure of the joint distributions. The parameters with the same distribution shape had the priority in the combining procedure. A joint distribution of two parameters was first produced - a joint distribution of the $\beta$ and $B C F$, and a joint distribution of the $(1-w)$ and $1 / B W a$. The type of the joint distributions with $10^{6}$ data was anew identified using a $\mathrm{K}-\mathrm{S}$ test. Moreover, an arithmetic average and an arithmetic standard deviation of normal distributions or a geometric average and a geometric standard deviation of log-normal distributions were computed from the joint distributions of $10^{6}$ data. The joint distribution of the $\beta$ and $B C F$ parameters agreed with a log-normal distribution of $\mathrm{LN}(1.45,4.43)$. The joint distribution of the $(1-w)$ and $1 /$ $B W a$ parameters also followed a log-normal distribution of $\mathrm{LN}\left(3.8 \times 10^{-3}, 1.20\right)$.

To reduce complicated computation, one thousand data were yielded from the joint distributions using MCA. A joint distribution of three parameters, $\beta, B C F$ and $I R_{w t}$, was then produced. Finally, a joint distribution of the five parameters, $\beta, B C F, I R_{w t},(1-w)$ and $(1 / B W a)$, was produced and agreed with a log-normal distribution of $\mathrm{LN}(0.51,4.94)$.
The other constant parameters in Eq. (3)-the $C_{R P W}$ of $50 \mu \mathrm{g} / \mathrm{L}$, the $\alpha$ of 0.32 and the constant value of $6.16 \times 10^{-4}$ -were adopted to calculate $T R_{t}$. Figure 4 displays a cumulative distribution of $T R_{t}$ and its frequency. Traditionally, the 5th, 25th, 50th, 75th and 95th percentiles of risks are displayed in a box-and-whiskers plot to assess different likelihoods of exceeding risk levels (US EPA 2001; Liu et al. 2005; Ling et al. 2005). The 5th, 25th, 50th, 75th and 95th percentiles determined from the $T R_{t}$ distribution are $3.5 \times 10^{-7}, 1.76 \times 10^{-6}, 5.46 \times 10^{-6}, 1.34 \times$ $10^{-5}$ and $6.01 \times 10^{-5}$, respectively.

To compare with other researches, the risks evaluated in this work are close to a risk range from $2.07 \times 10^{-6}$ to 7.89 $\times 10^{-5}$ reported by Ling et al. (2005), but are much lower than a risk range from $7.36 \times 10^{-4}$ to $1.12 \times 10^{-3}$ reported by Liao and Ling (2003). The unrealistic, high risks estimated by Liao and Ling (2003) result from the use of bioaccumulation factor to estimate As concentrations in tilapia, and the fail to convert the dry wt As concentration to wet wt and to ignore edible portions of tilapia.

\subsection{Establishment of risk-based arsenic regulation in pond water}

The current As regulation in drinking water, $10 \mu \mathrm{g} / \mathrm{L}$, was regarded as an important reference indicator when this study established a risk-based standard of As concentrations in pond water. Generally, two main factors greatly influence on results of risk assessment-inorganic As contents and ingestion rates. The different ingestion rates of tilapia and drinking water result in a great difference of risks. Therefore, the ingestion rates are inappropriately used to examine the current As regulation in pond water. On the contrary, the bioaccumulation relationship of inorganic As contents between tilapia and drinking water provides an important approach to explore the rationality of As regulations in farmed pond water via multiple exposure pathways.

According to a joint distribution of $C_{\text {pond }}, B C F$ and $(1-w)$, when tilapia was cultivated in pond water with the As concentration of $50 \mu \mathrm{g} / \mathrm{L}$, total As contents bioaccumulated from pond water were 348 and $1,888 \mu \mathrm{g} / \mathrm{kg}$ wet wt for an average level (the 50th percentile) and an extreme level (the 95th percentile) (Table 2), respectively. Inorganic As contents of the average and extreme levels were 17.5 and $188 \mu \mathrm{g} / \mathrm{kg}$ wet wt, respectively, acquired from a joint distribution of $C_{\text {pond }}, B C F(1-w)$ and $\beta$. Furthermore, most As in natural water originating from geological formation is in an inorganic form, even over $90 \%$ of total As [93\% reported in Chen et al. (1994) and $99 \%$ reported in Gault et al. (2005)]. This study assumed that the inorganic As concentration was $90 \%$ of the total As concentration in drinking water. The 

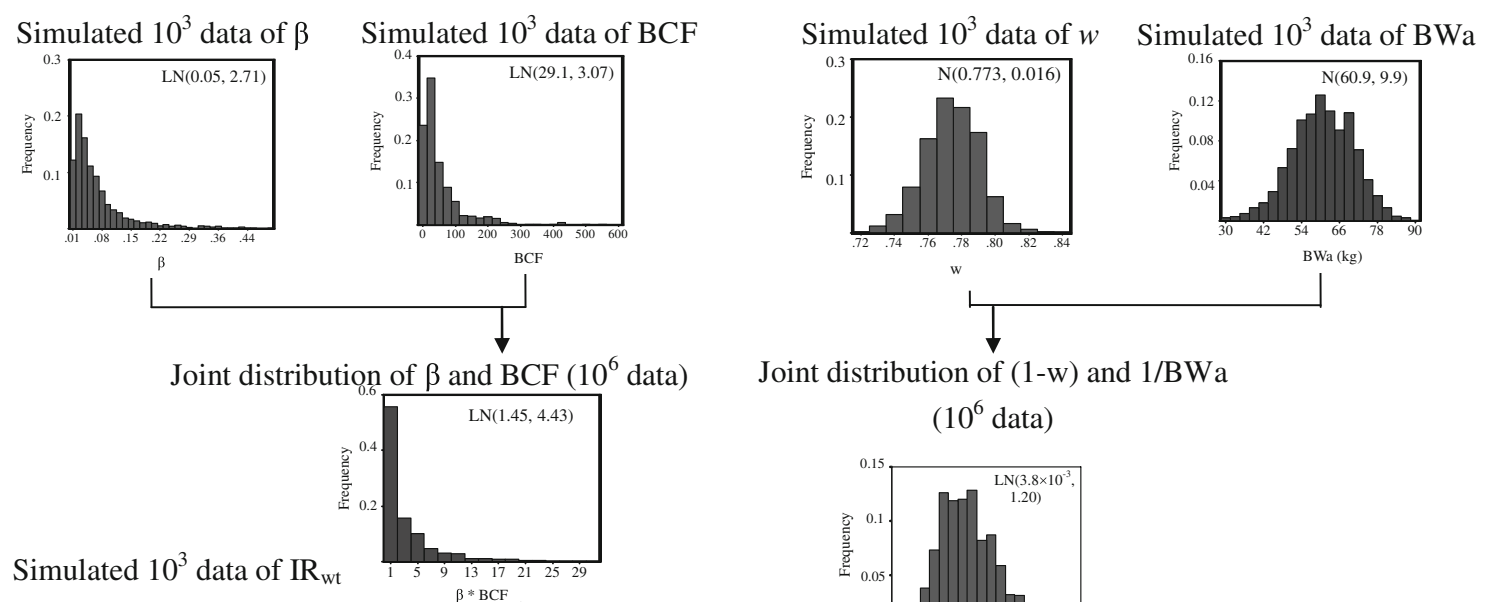

Joint distribution of (1-w) and 1/BWa

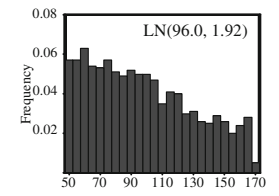

Simulated $10^{3}$ data from this joint distribution

$\operatorname{IR}_{\mathrm{w}}(\mathrm{g} /$ day wet $\mathrm{wt})$

Joint distribution of $\beta, \mathrm{BCF}$

and $\operatorname{IR}_{\mathrm{wt}}\left(10^{6}\right.$ data $)$

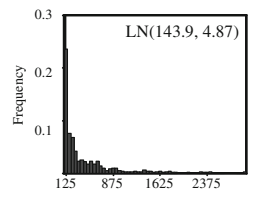

$\mathrm{B}^{*} \mathrm{BCF} * \mathrm{IR}_{\mathrm{wt}}$

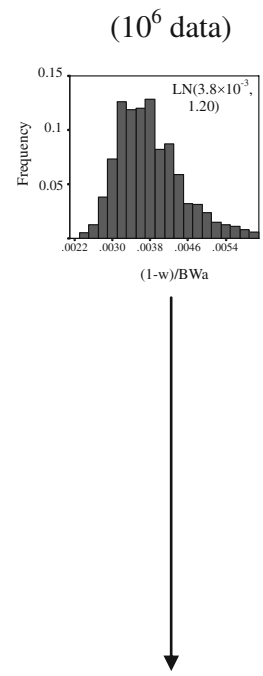

Simulated $10^{3}$ data from

Simulated $10^{3}$ data from

this joint distribution

this joint distribution

Joint distribution of $\beta, \mathrm{BCF}, \mathrm{IR}_{\mathrm{wt}},(1-\mathrm{w})$ and $1 / \mathrm{BWa}\left(10^{6}\right.$ data $)$

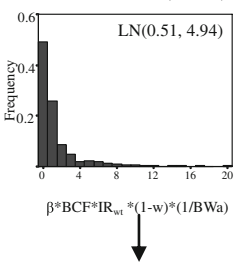

Multiplying the $\mathrm{C}_{\mathrm{RPW}}$ of $50 \mu \mathrm{g} / \mathrm{L}$, the $\alpha$ of 0.32 and the constant value of $6.16 \times 10^{-4}$

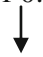

Calculating the $5^{\text {th }}, 25^{\text {th }}, 50^{\text {th }}, 75^{\text {th }}$ and $95^{\text {th }}$ percentiles

from $T R_{t}$ distribution

Performing risk assessment under

uncertainty conditions of five parameters

Fig. 3 Detailed processes of joint distributions and risk assessment

inorganic As concentration was thus $9 \mu \mathrm{g} / \mathrm{L}$ for the current As regulation in drinking water (Table 2). Although the unit of inorganic As contents in drinking water, $\mu \mathrm{g} / \mathrm{L}$, is different to that in tilapia, $\mu \mathrm{g} / \mathrm{kg}$, both of them are the unit of parts per billion (ppb). In term of risk assessment, the same amount of inorganic As contents in these units causes the same hazardous effect to human health. This study thus made a comparison of the amount of inorganic As contents between tilapia and drinking water. The analyzed result accounts for that the inorganic As contents of tilapia exceed those of drinking water under conditions of the current As regulations in farmed pond water and drinking water. According to the bioaccumulation relationship of inorganic As contents 


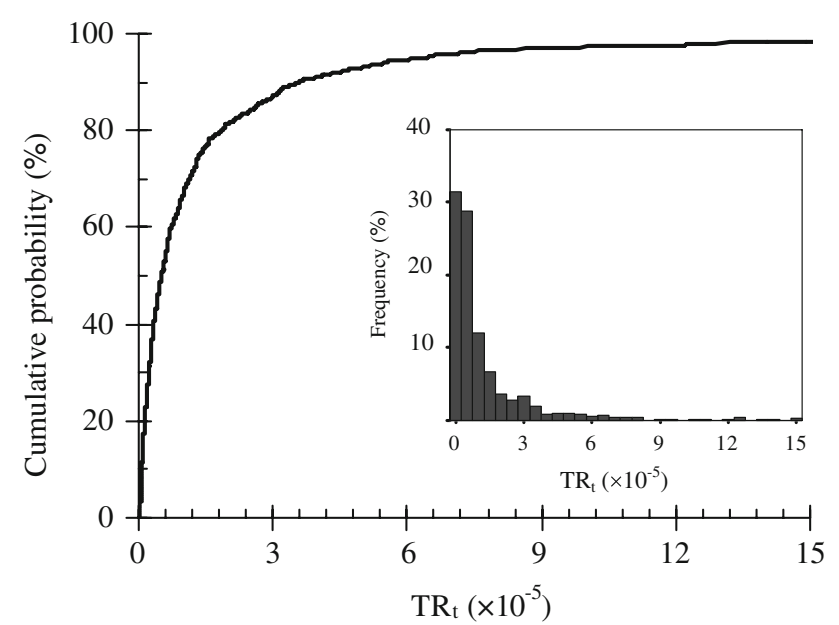

Fig. 4 Cumulative distribution and frequency of $T R_{t}$

between tilapia and drinking water, if we regard the current regulation of As concentration in drinking water as a rational and acceptable standard, the regulation of As concentration in farmed pond water should be considered to reduce to 25.7 and $2.4 \mu \mathrm{g} / \mathrm{L}$ under the average and extreme levels, respectively. However, the regulation of As concentration at the extreme level is too strict to be performed in the BFD hyperendemic areas. Even if the As concentrations of surface water in these regions cannot meet the level. Therefore, this work suggested that the rational regulation of As concentration in farmed pond water was $25 \mu \mathrm{g} / \mathrm{L}$, half of the current regulation in Taiwan. The range of As concentrations of $25-50 \mu \mathrm{g} / \mathrm{L}$ in farmed pond water, which is slightly higher than the regulation level of As in drinking water, is considered as an unsafe situation for human health.

A range of $10^{-6}$ to $10^{-4}$ is typically considered as an acceptable risk (Benner 2004). For the suggested As regulation in pond water, maximally and averagely exposed risks are $3.0 \times 10^{-5}$ and $2.7 \times 10^{-6}$, respectively, through ingesting tilapia farmed in the BFD hyperendemic area. Both of them fall into the range of the acceptable risk.

\subsection{Sensitivity analysis}

Because several parameters used in this assessment originated from our tilapia experiment or other surveys, they frequently exhibited variability and could impact on our analyzed results due to few observed data. Therefore, this work performed sensitivity analysis of parameters to explore the variability of the results. For the five parameters, $B C F, \beta, w, B W a$ and $I R_{w t}$, an arithmetic average or a geometric average determined from their observed distributions was used to calculate risks instead of probabilistic distributions reproduced by MCA. On the other hand, for the $\alpha$, a probability reproduced by MCA was used to compute risks instead of an arithmetic average. When certain parameter changes its original estimated approach, other parameters maintain their original one. Table 3 reports the 5th, 25th, 50th, 75th and 95th percentiles of risks for performing sensitivity analysis of parameters. Changes in most parameters do not seriously impact on the 5 th, 25th, and 50th percentiles of risks. However, changes in the $\beta$ and $B C F$ significantly influence on the risk assessment at the 75th and 95th percentiles. Thus, the change in parameters less influences on the recommended regulation of As concentration of $25 \mu \mathrm{g} / \mathrm{L}$ in farmed pond water because it was determined according to the average level of risks.

\subsection{Management strategy of arsenic-contaminated groundwater}

Because of several advantages of groundwater utilization, such as convenient acquisition, low expense of withdrawal and elevating temperature in farmed pond water in winter, As-contaminated groundwater is still used inevitably in BFD hyperendemic regions. A risk-based scheme associated with the dynamic management of As-contaminated groundwater use was proposed in this study. For no adverse health effects, the proportion of the mixture between groundwater and surface water used in farmed pond water

Table 2 Comparison of inorganic As contents of the current As regulations between drinking water and pond water

\begin{tabular}{|c|c|c|c|}
\hline Items & $\begin{array}{l}\text { Total As content } \\
\text { of water }(\mu \mathrm{g} / \mathrm{L})\end{array}$ & $\begin{array}{l}\text { Total As content } \\
\text { of tilapia }(\mu \mathrm{g} / \mathrm{kg} \text { wet } \mathrm{wt})\end{array}$ & Inorganic As content \\
\hline (1) Drinking water & 10 & - & $9^{\mathrm{b}} \mu \mathrm{g} / \mathrm{L}$ \\
\hline (2) Pond water (average level - the 50th percentile) & 50 & $348^{\mathrm{a}}$ & $17.5^{\mathrm{c}} \mu \mathrm{g} / \mathrm{kg}$ wet wt \\
\hline (3) Pond water (extreme level - the 95th percentile) & 50 & $1,888^{\mathrm{a}}$ & $188^{\mathrm{c}} \mu \mathrm{g} / \mathrm{kg}$ wet wt \\
\hline$(1) /(2)$ & - & - & 0.514 \\
\hline$(1) /(3)$ & - & - & 0.048 \\
\hline
\end{tabular}

${ }^{\text {a }}$ Obtained from a joint distribution of $C_{\text {pond }} \times B C F \times(1-w)$, and the $C_{\text {pond }}$ is $50 \mu \mathrm{g} / \mathrm{L}$

b Obtained from $\mathrm{C}_{\text {drinking }} \times 0.9$

${ }^{\mathrm{c}}$ Obtained from a joint distribution of $C_{\text {pond }} \times B C F \times(1-w) \times \beta$, and the $C_{\text {pond }}$ is $50 \mu \mathrm{g} / \mathrm{L}$ 
Table 3 The 5th, 25th, 50th, 75th, and 95th percentiles of risks for the sensitivity analysis of parameters

\begin{tabular}{llllll}
\hline Parameters & \multicolumn{5}{l}{ Percentiles of risks $\left(\times 10^{-6}\right)$} \\
\cline { 2 - 6 } & 5 th & 25 th & 50 th & 75 th & 95 th \\
\hline Original estimates & 0.35 & 1.76 & 5.46 & 13.4 & 60.1 \\
$B W a$ & 0.35 & 1.75 & 5.32 & 12.9 & 55.0 \\
$\alpha$ & 0.35 & 1.77 & 5.35 & 13.4 & 62.0 \\
$\beta$ & 0.69 & 2.28 & 5.37 & 11.2 & 32.1 \\
$w$ & 0.35 & 1.79 & 5.50 & 13.4 & 59.6 \\
$B C F$ & 0.73 & 2.35 & 4.83 & 10.2 & 27.9 \\
$I R_{w t}$ & 0.43 & 2.04 & 5.68 & 13.5 & 58.8 \\
\hline
\end{tabular}

was computed based on the suggested and current As regulations. Additionally, the term $C_{\text {surface }}$ in Eq. (5) was assumed to be $5 \mu \mathrm{g} / \mathrm{L}$.

Figure 5 plots curves of $U R$ versus As concentrations in groundwater based on the As regulations of 25 and $50 \mu \mathrm{g} /$ L. The relationship between $U R$ and As concentrations in groundwater is divided into three compartments-safe zone $(\mathrm{S})$, unsafe zone $(\mathrm{U})$, and hazardous zone $(\mathrm{H})$. The As concentration in farmed pond water is under $25 \mu \mathrm{g} / \mathrm{L}$ for the safe zone; between 25 and $50 \mu \mathrm{g} / \mathrm{L}$ for the unsafe zone and over $50 \mu \mathrm{g} / \mathrm{L}$ for the hazardous zone. According to the proposed curves and measured As concentrations in groundwater used in ponds, an appropriate $U R$ using surface water can be evaluated for no adverse health effects. Thus, each fish pond in the regions possesses its optimal $U R$ based on the As concentration of groundwater used in the fish pond. If surface water sufficiently meets the aquacultural needs in the BFD hyperendemic regions, the safe relationship between $U R$ and As concentrations in groundwater could be enforced. Meanwhile, the unsafe relationship should be maintained at least in a dry season when surface water is limited.

Jang et al. (2006) reported in situ eight sets of field data on As concentrations in groundwater and ponds. Figure 5 marks the data-sets against the relationship between As concentrations and UR. Two sets of data are in the safe zone; three sets of data are in the unsafe zone and three sets of data are in the hazardous zone. The analyzed result reveals that higher As concentrations in groundwater are used in fish pond to produce easily higher adverse effects on human health. However, the As concentrations in groundwater ranging from 13.2 to 254 $\mu \mathrm{g} / \mathrm{L}$ in this survey are considerably lower than those reported in Tseng (1977), ITRI (1993) and Jang et al. (2006). Arsenic concentrations in groundwater of over $400 \mu \mathrm{g} / \mathrm{L}$ are not recommended to cultivate fish because a difficult operation condition, a very low $U R$, requires to be met $(<0.051$ and $<0.115$ for As regulations of 25 and $50 \mu \mathrm{g} / \mathrm{L}$, respectively).

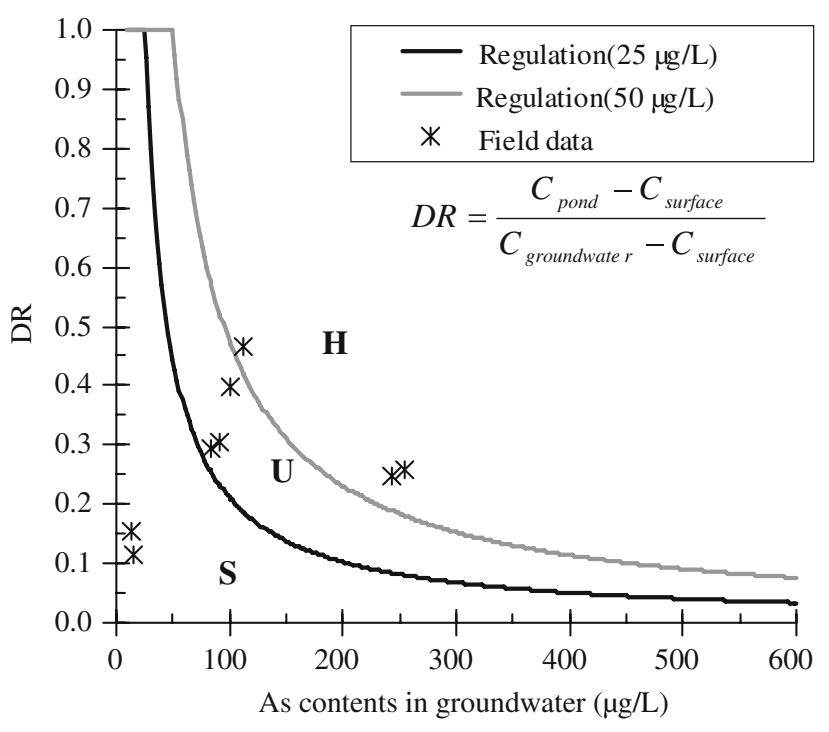

Fig. 5 Curves of risk management of groundwater use. $S$ is the safe zone; $U$ is the unsafe zone and $H$ is the hazardous zone

\section{Conclusion}

This work presented a risk-based regulation of As in farmed pond water via consuming tilapia in BFD hyperendemic regions of Taiwan. Owing to sparse measured data on tilapia experiment, the probabilistic approach can properly propagate uncertainty of parameters and establish a robust framework of risk assessment. The analyzed result indicates that the 5th to 95 th percentiles of risks range from $3.5 \times 10^{-7}$ to $6.0 \times 10^{-5}$ via ingesting tilapia under the current regulation of As in farmed pond water. According to the relationship of inorganic As contents between tilapia and drinking water, the current regulation of As in farmed pond water, $50 \mu \mathrm{g} / \mathrm{L}$, does not pose a great menace to human health but cause unsafe effects to human health. Consequently, this study suggests that the regulation of As in farmed pond water is revised to be $25 \mu \mathrm{g} / \mathrm{L}$. Maximally and averagely exposed risks are $3.0 \times 10^{-5}$ and $2.7 \times 10^{-}$ 6 , respectively, according to the revised regulation. Furthermore, a dynamic scheme of groundwater management was proposed in BFD hyperendemic regions. Curves of $U R$ versus As concentrations in groundwater were established based on the risk-based regulation of As. When the Ascontaminated groundwater is used to cultivate fish, a proper $U R$ diluted using surface water obtained from the curves should be considered for water operation of each pond. Although this study only considers single fish species farmed in the BFD hyperendemic area to evaluate the rationality of the current As regulation in pond water, the assessed findings offer a risk-based framework for examining the regulation. In the future, this analyzed approach can be adopted for other species of fish farmed in the BFD hyperendemic area and verify whether the revised 
regulation of As concentrations in pond water is of no adverse health effects for other species of fish. Furthermore, this study also provides a useful reference for establishing standards of aquicultural safety in other worldwide regions with highly As-contaminated groundwater, such as Bangladesh (Al Rmalli et al. 2005).

Acknowledgments The authors would like to thank the National Science Council of the Republic of China for financially supporting this research under Contracts Nos. NSC90-2313-B-002-322 and NSC91-2313-B-002-270.

\section{References}

Al Rmalli SW, Haris PI, Harrington CF, Ayub M (2005) A survey of arsenic in foodstuffs on sale in the United Kingdom and imported from Bangladesh. Sci Total Environ 337:23-30

Benner TC (2004) Brief survey of EPA standard-setting and health assessment. Environ Sci Technol 38:3457-3464

Cao H-C, Luan Z-Q, Wang J-D, Zhang X-L (2008) Potential ecological risk of cadmium, lead and arsenic in agricultural black soil in Jilin Province, China. Stoch Environ Res Risk Assess. doi:10.1007/s00477-007-0195-1

Chen C-J, Wang C-J (1990) Ecological correlation between arsenic level in well water and aged-adjusted mortality from malignant neoplasms. Cancer Res 50:5470-5474

Chen C-J, Hsueh Y-M, Lai M-S, Shyu M-P, Chen S-Y, Wu M-M, Kuo T-L, Tai T-Y (1995) Increased prevalence of hypertension and long-term arsenic exposure. Hypertension 25:53-60

Chen S-L, Dzeng S-R, Yang M-H, Chiu K-H, Shieh G-M, Wai C-M (1994) Arsenic species in groundwaters of the blackfoot disease area, Taiwan. Environ Sci Technol 28:877-881

Gault AG, Jana J, Chakraborty S, Mukherjee P, Sarkar M, Nath B, Polya DA, Chatterjee D (2005) Preservation strategies for inorganic arsenic species in high iron, low-Eh groundwater from West Bengal, India. Anal Bioanal Chem 381:347-353

Goovaerts P, Semrau JM, Lontoh S (2001) Monte Carlo analysis of uncertainty attached to microbial pollutant degradation rates. Environ Sci Technol 35:3924-3930

Han B-C, Jeng W-L, Chen R-Y, Fang G-T, Hung T-C, Tseng R-J (1998) Estimation of target hazard quotients and potential health risks for metals by consumption of seafood in Taiwan. Arch Environ Contam Toxicol 35:711-720

Huang Y-K, Lin K-H, Chen H-W, Chang C-C, Liu C-W, Yang M-H, Hsueh Y-M (2003) Arsenic species contents at aquaculture farm and in farmed mouthbreeder (Oreochromis mossambicus) in blackfoot disease hyperendemic areas. Food Chem Toxicol 41:1491-1500

Hung CL-H, So M, Connell DW, Fung C-N, Lam MH-W, Nicholson S, Richardson BJ, Lam PK-S (2004) A preliminary risk assessment of trace elements accumulated in fish to the IndoPacific Humpback dolphin (Sousa chinensis) in the Northwestern waters of Hong Kong. Chemosphere 56:643-651

ITRI (Industrial Technology Research Institute) (1993) Project of Arsenic Contents in Drinking-water Wells in Blackfoot Disease Hyperendemic Areas. Taiwan Environmental Protection Agency (EPA-82-J102-09-10), Taiwan (in Chinese)

Jang C-S, Liu C-W, Lin K-H, Huang F-M, Wang S-W (2006) Spatial analysis of potential carcinogenic risks associated with ingesting arsenic in aquacultural tilapia (Oreochromis mossambicus) in blackfoot disease hyperendemic areas. Environ Sci Technol 40:1707-1713
Kentel E, Aral MM (2005) 2D Monte Carlo versus 2D Fuzzy Monte Carlo health risk assessment. Stoch Environ Res Risk Assess 19:86-96

Lai M-S, Hsueh Y-M, Chen C-J, Shyu M-P, Chen S-Y, Kuo T-L, Wu M-M, Tai T-Y (1994) Ingested inorganic arsenic and prevalence of diabetes mellitus. Am J Epidemiol 139:484-492

Liao C-M, Ling M-P (2003) Assessment of human health risks for arsenic bioaccumulation in tilapia (Oreochromis mossambicus) and large-scale mullet (Liza macrolepis) from blackfoot disease area in Taiwan. Arch Environ Contam Toxicolo 45:264-272

Lin K-H (2004) Spatiotemporal distribution and bioaccumulation of arsenic species in the aquacultural ecosystem in the coastal areas of Southwestern Taiwan (in Chinese). PhD Dissertation, Institute of Bioenvironmental Systems Engineering, National Taiwan University, Taiwan, pp 176-197

Ling M-P, Liao C-M, Tsai J-W, Chen B-C (2005) A PBPK/PD modeling-based approach can assess arsenic bioaccumulation in farmed tilapia (Oreochromis mossambicus) and human health risks. Integr Environ Assess Manag 1:40-54

Liu C-W, Huang F-M, Hsueh Y-M (2005) Revised cancer risk assessment of inorganic arsenic upon consumption of tilapia (Oreochromis mossambicus) from blackfoot disease hyperendemic areas. Bull Environ Contam Toxicol 74:1037-1044

Liu C-W, Wang S-W, Jang C-S, Lin K-H (2006) Occurrence of arsenic in groundwater of the Choshui river alluvial fan, Taiwan. J Environ Qual 35:68-75

Mandal BK, Suzuki KT (2002) Arsenic round the world: a review. Talanta 58:201-235

McGeer JC, Brix KV, Skeaff JM, DeForest DK, Brigham SI, Adams WJ, Green A (2003) Inverse relationship between bioconcentration factor and exposure concentration for metals: Implications for hazard assessment of metals in the aquatic environment. Environ Toxicol Chem 22:1017-1037

Oremland RS, Stotlz JF (2003) The ecology of arsenic. Science 300:939-944

Pohl HR, Roney N, Wilbur S, Hansen H, De Rosa CT (2003) Six interaction profiles for simple mixtures. Chemosphere 53:183197

Shiomi K, Suglyama Y, Shimakura K, Nagashima Y (1996) Retention and biotransformation of arsenic compounds administered intraperitoneally to carp. Fish Sci 62:261-266

Taiwan DOH (1997) Survey of Taiwanese nutrition and health of 1996 (in Chinese). Department of Health, Executive Yuan, Taiwan. http://www.doh.gov.tw/statistic/index.htm.

Taiwan EPA (1998) Classification and Standards of Water Quality in Surface Water (in Chinese). Taiwan Environmental Protection Agency, Taiwan

Taiwan Sugar Company (2002) Establishment and operational management of groundwater monitoring network (in Chinese). Water Resources Bureau, Taiwan, pp 2-12

Tseng W-P (1977) Effects and dose-response relationships of skin cancer and blackfoot disease with arsenic. Environ Health Perspect 19:109-119

US EPA (1988) Special report on ingested inorganic arsenic: skin cancer; nutritional essentiality. EPA/625/3-87/013, US Environmental Protection Agency, Risk Assessment Forum, Washington, DC

US EPA (2001) Risk assessment guidance for superfund. In: Process for conducting probabilistic risk assessment, volume III, Part A. US Environmental Protection Agency EPA 540-R-02-002, Washington, DC

US EPA (2006) Risk-based concentration table, region 3. US Environmental Protection Agency, Philadelphia. http://www.epa. gov/ reg3hwmd/risk/human/index.htm Accessed October 2006

Wu M-M, Kuo T-L, Hwang Y-H, Chen C-J (1989) Dose-response relation between arsenic concentration in well water and 
mortality from cancers and vascular diseases. Am J Epidemiol 130:1123-1132

Yu H-L, Kolovos A, Christakos G, Chen J-C, Warmerdam S, Dev B (2007) Interactive spatiotemporal modelling of health systems: the SEKS-GUI framework. Stoch Environ Res Risk Assess 21:555-572

Yu W-H, Harvey CM, Harvey CF (2003) Arsenic in groundwater in Bangladesh: a geostatistical and epidemiological framework for evaluating health effects and potential remedies. Water Resour Res 39:1146-1151 doi:10.1029/2002WR001327

Zakharova T, Tatàno F, Menshikov V (2002) Health cancer risk assessment for arsenic exposure in potentially contaminated areas by fertilizer plants: a possible regulatory approach applied to a case study in Moscow region-Russia. Regul Toxicol Pharmacol 36:22-33 